\title{
Kinerja Keuangan Entitas Multifinance: Determinasi Non Performing Loan dan Capital Adequacy Ratio Terhadap Profitabilitas
}

\author{
Andi Riyanto ${ }^{1}$, Galih Raspati ${ }^{2}$, Yuri Rahayu ${ }^{3}$, Yuyun Yuniati $^{4}$ \\ ${ }^{1,3}$ Universitas Bina Sarana Informatika \\ e-mail: ${ }^{1}$ andi.iio@bsi.ac.id, ${ }^{3}$ yuri.yru@bsi.ac.id \\ ${ }^{2}$ Institut Manajemen Wiyata Indonesia \\ e-mail: ${ }^{2}$ galih_raspati@yahoo.com \\ ${ }^{4}$ STIE Pasim \\ e-mail: ${ }^{4}$ yuyunyuniati37@gmail.com

\begin{tabular}{ccc}
\hline Diterima & Direvisi & Disetujui \\
$07-07-2021$ & $21-07-2021$ & $15-09-2021$ \\
\hline
\end{tabular}

\begin{abstract}
Abstrak - Pada perusahaan pembiayaan, profit merupakan hal mutlak untuk diperoleh agar dapat mempertahankan kontinuitas operasional perusahaan. Oleh karena itu, tujuan utama perusahaan yaitu meningkatkan profitabilitas agar dapat menghasilkan keuntungan yang maksimal. Dalam menjalankan usaha dan aktivitasnya, perusahaan tidak lepas dari masalah kredit bermasalah atau Non Performing Loan (NPL) dan permodalan atau Capital Adequacy Ratio (CAR) yang mempengaruhi profitabilitas, artinya perusahaan harus mampu meningkatkan profitabilitas, menekan NPL dan menerapkan kriteria CAR. Tinggi rendahnya rasio NPL dan CAR mempunyai impak terhadap besar kecilnya profitabilitas. Metode penelitian yang digunakan adalah metode penelitian ex post facto dengan pendekatan kuantitatif. Data yang digunakan adalah data keuangan tentang kredit bermasalah dengan total kredit, modal dengan Aktiva Tertimbang Menurut Risiko (ATMR) dan profitabilitas atau Return On Assets (ROA) dengan membandingkan laba setelah pajak dengan total aset pada laporan keuangan 2012-2019. Teknik pengujian menggunakan uji statistik. Hasil penelitian yang didapatkan menyatakan bahwa NPL dan CAR berpengaruh secara simultan terhadap tingkat profitabilitas pada PT. Adira Dinamika Multi Finance, Tbk.
\end{abstract}

Kata Kunci: Kinerja Keuangan Multifinance, Non Performing Loan (NPL), Capital Adequacy Ratio, Profitabilitas

Abstract - In finance companies, profit is an absolute thing to be obtained in order to maintain the continuity of the company's operations. Therefore, the main goal of the company is to increase profitability in order to generate maximum profits. In running its business and activities, the company cannot be separated from problem loans or Non Performing Loans (NPL) and capital or Capital Adequacy Ratio (CAR) which affect profitability, meaning that companies must be able to increase profitability, suppress NPL and apply CAR criteria. The high and low ratio of NPL and CAR has an impact on the size of profitability. The research method used is an ex post facto research method with a quantitative approach. The data used are financial data on non-performing loans with total credit, capital with Risk Weighted Assets (RWA) and profitability or Return On Assets (ROA) by comparing profit after tax with total assets in the 2012-2019 financial statements. The test technique uses statistical tests. The results of this study indicate that NPL and CAR simultaneously affect the level of profitability at PT. Adira Dinamika Multi Finance, Tbk.

Keywords: Multifinance Financial Performance, Non Performing Loan (NPL), Capital

\section{PENDAHULUAN}

Kinerja dapat merupakan hasil dari keputusan dan tindakan entitas yang dapat diukur yang mencerminkan kinerja entitas dalam mencapai keberhasilan dan pencapaian. Evaluasi kinerja entitas diperlukan dan standar yang diterima harus digunakan untuk tujuan ini agar mempertimbangkan berbagai aspek keterbatasan dalam kegiatan dan peluang untuk menggunakan berbagai fasilitas operasional yang ada. Berbagai kriteria telah digunakan untuk mengevaluasi dan mengukur kinerja unit bisnis dalam studi akuntansi dan penelitian yang dapat diklasifikasikan dalam dua kategori umum kriteria berbasis pasar dan kriteria berbasis data akuntansi. Oleh karena itu, untuk meneliti hubungan antara tata kelola perusahaan dan kinerja unit bisnis, kriteria berbasis data akuntansi lebih unggul dari 
kriteria berbasis pasar (Rostami, Rostami, \& Kohansal, 2016). Kriteria berbasis data akuntansi mampu memberikan solusi bagaimana perusahaan mencapai tujuan keuangannya.

Sepanjang 2020, akibat pandemi Covid-19, diversifikasi industri keuangan mengalami tekanan luar biasa. Selain itu mempertahankan jumlah kredit bermasalah yang tinggi pada neraca dapat mengganggu penyediaan kredit untuk ekonomi riil, melalui volume yang lebih rendah, pinjaman kepada peminjam berisiko atau harga bisa lebih tinggi, dapat berkontribusi negatif terhadap pemulihan setelah krisis keuangan (Sánchez Serrano, 2021). Namun, banyak perusahaan keuangan yang dapat bertahan. Penurunan kinerja keuangan industri multifinance disebabkan adanya pembatasan aktivitas masyarakat untuk mengurangi risiko penyebaran virus. Banyak pihak menyatakan bahwa, terutama akibat pengaruh kebijakan pemerintah, khususnya kebijakan restrukturisasi kredit, tren penurunan bisnis multifinance sepanjang tahun 2020 cenderung lebih terkendali. Alhasil, hingga akhir tahun 2020 rasio kredit bermasalah (Non Performance Finance atau NPL) bisa diturunkan menjadi 4,01\% (Ovier, 2021). Dalam sistem ekonomi yang berpusat pada perbankan, bank dan lembaga finansial memainkan peran kunci sebagai bagian dalam keberlanjutan sistem perbankan dan dikenal sebagai sumber utama pendanaan (Moradi, Mirzaeenejad, \& Geraeenejad, 2016).

PT. Adira Dinamika Multi Finance merupakan salah satu perusahaan multifinance yang mampu bertahan ditengah tekanan yang luar biasa akibat pandemi Covid-19. Entitas membukukan laba bersih tahun 2019 lalu mencapai Rp 2,1 triliun. Pencapaian ini tumbuh $16 \%$ setiap tahun. Sedangkan pencapaian Return on Assets (ROA) mencapai 6,3 persen. Jumlah NPL naik menjadi 1,6 persen dari nilai piutang di tahun 2019, dibandingkan dengan 1,7 persen di tahun 2018 (Gunawan, 2020).

Pada perusahaan pembiayaan laba merupakan hal yang mutlak untuk diperoleh, agar dapat mempertahankan kontinuitas perusahaan. Kemudian untuk mengukur tingkat laba suatu perusahaan, digunakan rasio profitabilitas. Profitabilitas dalam penelitian ini diproksikan sebagai Return On Assets (ROA) yang berfokus pada kemampuan perusahaan memperoleh laba dalam operasi perusahaan dengan memanfaatkan aset yang dimilikinya..

Tingkat aset yang baik dapat mempengaruhi laba entitas multifinance. Hal ini terlihat pada jumlah modal yang mempengaruhi tingkat kepercayaan masyarakat terhadap kinerja entitas. Tingkat alokasi kredit yang baik atau kualitas kredit yang baik juga akan mempengaruhi tingkat laba dari entitas multifinance.

Berdasarkan uraian diatas, maka masalah pokok pada riset ini dapat dirumuskan sebagai berikut:
1. Bagaimana impak NPL tehadap tingkat profitabilitas (ROA).

2. Bagaimana impak CAR tehadap tingkat profitabilitas (ROA).

3. Bagaimana impak NPL dan CAR tehadap tingkat Profitabilitas (ROA).

Sedangkan maksud dan tujuan yang hendak dicapai adalah:

1. Untuk mengetahui impak NPL tehadap tingkat profitabilitas (ROA).

2. Untuk mengetahui impak CAR tehadap tingkat profitabilitas (ROA).

3. Untuk mengetahui impak NPL dan CAR tehadap tingkat profitabilitas (ROA).

NPL sangat dipengaruhi oleh variabel makro, seperti pertumbuhan Produk Domestik Bruto (PDB), pengangguran dan inflasi, dan yang terkait dengan variabel bank, seperti manajemen dan struktur pasar yang buruk (Beck, Jakubik, \& Piloiu, 2015; Anastasiou, Louri, \& Tsionas, 2019). Pada sisi yang lain krisis moneter sangat ditandai oleh kenaikan kredit bermasalah (NPL) pada perbankan (Khan, Siddique, \& Sarwar, 2020)

NPL adalah pinjaman yang belum dibayar. International Monetary Fund (IMF) menyatakan bahwa pinjaman dianggap sebagai NPL jika tidak menghasilkan bunga dan jumlah pokok minimal untuk 90 hari (Khan et al., 2020). Kemudian pinjaman menjadi NPL jika prinsipal jumlah dan bunganya belum dibayar pada tanggal jatuh tempo dan tidak diantisipasi di masa depan (Gilbert \& Hazen, 2001).

NPL merupakan salah satu rasio kinerja keuangan yang sering diterapkan pada perusahaan multifinance (Sitompul, Bukit, \& Erwin, 2020). Rasio NPL naik ketika pertumbuhan ekonomi melambat dan berisiko enggan menurun ketika suku bunga meningkat (Espinoza \& Prasad, 2010).

Capital Adequacy Ratio (CAR) didefinisikan sebagai rasio yang digunakan untuk mengukur modal dan penghapusan cadangan dalam menutupi kredit, terutama risiko yang terjadi karena bunga gagal ditagih (Anggari \& Dana, 2020). Selain itu CAR adalah penyediaan modal minimum bagi bank berdasarkan risiko aktif dalam arti yang seluasluasnya, baik aset yang tercantum dalam neraca maupun aset administratif sebagai tercermin dalam kewajiban yang masih bersifat kontinjensi dan/atau komitmen yang diberikan oleh bank kepada pihak ketiga serta risiko pasar (Bank Indonesia, 2011). Peran kunci dari rasio ini adalah untuk menahan halhal yang tidak terduga seperti kerusakan atau kejutan akibat perilaku pengambilan risiko yang berlebihan dari lembaga finansial (Ashraf, Arshad, \& Hu, 2016). Maka disimpulkan CAR merupakan alat ukur finansial dalam mengukur tingkat modal berdasarkan risiko yang mungkin terjadi yang bertujuan meminimalkan kerugian akibat risiko tersebut pada lembaga finansial. 
Profitabilitas adalah rasio yang mengukur kemampuan perusahaan untuk menghasilkan keuntungan dari operasi normal perusahaan (Utami \& Manda, 2021; Sari \& Khafid, 2020). Profitabilitas juga merupakan salah satu margin keuntungan yang biasanya digunakan untuk mengukur kemampuan perusahaan dalam menghasilkan laba bersih berdasarkan tingkat asetnya. Rasio profitabilitas menunjukkan semakin tinggi rasio ROA maka semakin efisien perusahaan menggunakan asetnya untuk menghasilkan laba bersih (Pattiruhu \& Paais, 2020).

Berdasarkan latar belakang, rumusan masalah dan tujuan penelitian maka kerangka konseptual pada penelitian ini dapat digambarkan sebagai berikut:

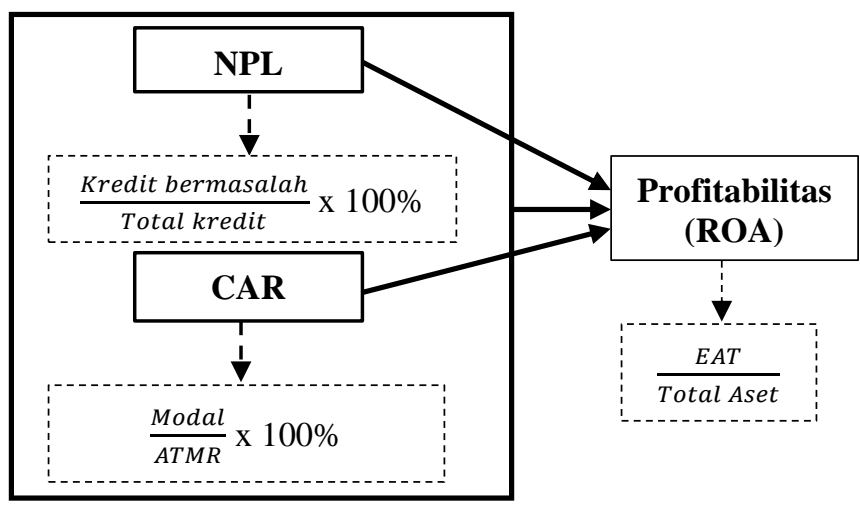

Gambar 1. Kerangka Konseptual

Kemudian berdasarkan kerangka konseptual pada gambar 1 maka dirumuskan hipotesis yang menyatakan patut di duga terdapat impak Non Performing Loan (NPL) dan Capital Adequacy Ratio (CAR) terhadap Profitabilitas (ROA).

\section{METODE PENELITIAN}

\section{Rancangan Penelitian}

Metode penelitian yang diambil dalam penelitian ini adalah metode Ex Post Facto, yaitu melakukan penelitian untuk mengkaji peristiwa yang telah terjadi, kemudian menelusuri kembali untuk mengetahui apa yang mungkin menyebabkan peristiwa tersebut (Sugiyono, 2017).

\section{Populasi}

Populasi adalah suatu kelompok, baik individu maupun besar yang memiliki karakteristik yang sama atau serupa dari kesatuan sampel yang hendak diteliti (Neuman, 2014; Creswell, 2016).

Penelitian ini menggunakan populasi seluruh laporan keuangan PT. Adira Dinamika Multi Finance, Tbk dari tahun 2012 sampai 2019.

\section{Sampel}

Sampel adalah bagian dari populasi yang akan ikut serta dalam penelitian, merupakan bagian yang representatif dan mewakili karakteristik populasi (Neuman, 2014).
Teknik pengambilan sampel yang digunakan adalah teknik non probability sampling yaitu yang tidak memberi peluang atau kesempatan sama bagi setiap unsur atau anggota populasi untuk dipilih menjadi sampel dengan cara menetapkan sampling kuota yaitu menentukan sampel yang mempunyai karakteristik tertentu sampai jumlah (kuota) yang diinginkan (Sugiyono, 2017). Maka sampel yang akan diambil dalam penelitian ini adalah laporan keuangan tahun 2012 - 2019 PT. Adira Dinamika Multi Finance Tbk.

\section{Hipotesis Statistik}

Hubungan dari kedua jenis variabel yang diteliti yaitu variabel X1, X2 dan variabel $Y$, dapat dilihat dengan menggunakan uji t dan uji $F$.

Uji t digunakan untuk menguji implikasi tiaptiap variabel bebas yang digunakan dalam penelitian terhadap beberapa variabel terikat (Ghozali, 2016).

\section{Uji Asumsi Klasik}

Sebelum dilakukan pengujian analisis regresi linier berganda terhadap hipotesis penelitian, maka terlebih dahulu perlu dilakukan suatu pengujian untuk mengetahui ada atau tidaknya pelanggaran terhadap asumsi-asumsi klasik. Tujuan dari uji ini digunakan sebagai identifikasi ada tidaknya estimator linear yang baik dari model regresi. Model regresi linier berganda dikatakan baik jika data terbebas dari asumsi-asumsi klasik dan menurut (Basuki, 2017) terdiri dari normalitas, multikolinieritas, heteroskedastisitas dan autokorelasi.

\section{Analisis Korelasi}

Analisis korelasi bertujuan untuk mengetahui kekuatan hubungan antara variabel bebas dan variabel terikat sebagian atau sekaligus (Amelia \& Sunarsi, 2020).

Untuk dapat menjelaskan apakah koefisien korelasi yang ditemukan besar atau kecil, dapat merujuk pada kriteria yang tercantum pada tabel 1 di bawah ini:

Tabel 1. Kriteria Keeratan Koefisien Korelasi

\begin{tabular}{|c|c|}
\hline Interval Koefisien & Tingkat Hubungan \\
\hline $0,00-0.199$ & Sangat Rendah \\
\hline $0,20-0.399$ & Rendah \\
\hline $0,40-0,599$ & Sedang \\
\hline $0,60-0,799$ & Kuat \\
\hline $0,80-1,000$ & Sangat Kuat \\
\hline
\end{tabular}

Sumber: (Sugiyono, 2017).

\section{Koefisien Determinasi}

Koefisien determinasi digunakan untuk menentukan seberapa besar variabel independen mempengaruhi sebagian dari variabel dependen baik secara parsial maupun simultan dan untuk mengevaluasi kecocokan model dengan data (Sugiyono, 2017); Amelia \& Sunarsi, 2020; Sugiarti \& Megawarni, 2012).

\section{Analisis Regresi Linier Berganda}


Regresi linier berganda dirancang untuk menguji pengaruh dua atau lebih variabel bebas (explanatory) terhadap satu variabel terikat (Janie, 2012; Yuliara, 2016).

\section{HASIL DAN PEMBAHASAN}

\section{Uji Normalitas}

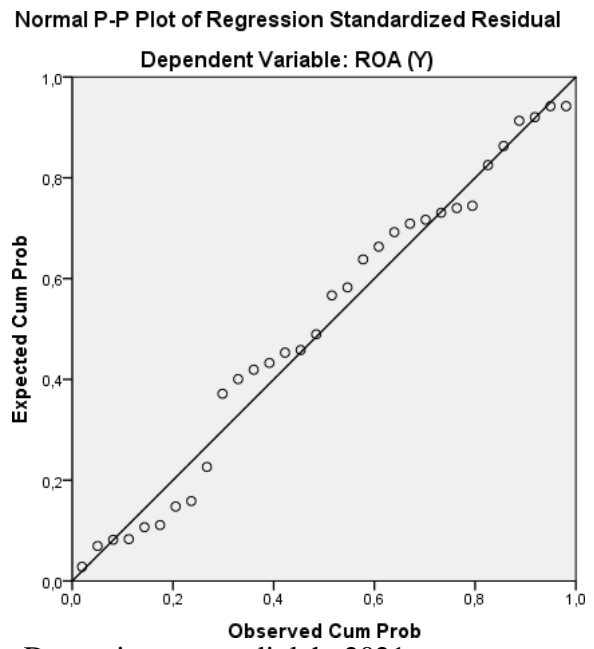

Sumber: Data primer yang diolah, 2021.

\section{Gambar 2. Hasil Uji Normalitas}

Berdasarkan gambar 2 menunjukkan model regresi berdistribusi normal karena data ploting (titiktitik)

\begin{tabular}{|c|c|}
\hline \multicolumn{2}{|c|}{ Collinearity Statistics } \\
\cline { 2 - 3 } Tolerance & VIF \\
\hline, 963 & 1,038 \\
\hline, 963 & 1,038 \\
\hline
\end{tabular}

menggambarkan data sesungguhnya karena mengikuti garis diagonal.

\section{Uji Multikolinearitas}

Tabel 2. Hasil Uji Multikolinearitas

\begin{tabular}{|l|l|}
\hline \multicolumn{2}{|c|}{ Collinearity Statistics } \\
\hline Tolerance & VIF \\
\hline, 963 & 1,038 \\
\hline, 963 & 1,038 \\
\hline
\end{tabular}

Sumber: Data primer yang diolah, 2021.

Hasil uji multikolinieritas pada tabel 2 menunjukkan nilai toleransi untuk NPL sebesar 0,963 dan CAR sebesar 0,963 yang berarti mempunyai kriteria $>0,1$. Nilai VIF NPL sebesar 1,038 dan CAR sebesar 1,038 yang berarti mempunyai nilai VIF < 10. Ini menunjukkan NPL dan CAR tidak ada gejala multikolinieritas.

Uji Heteroskedastisitas

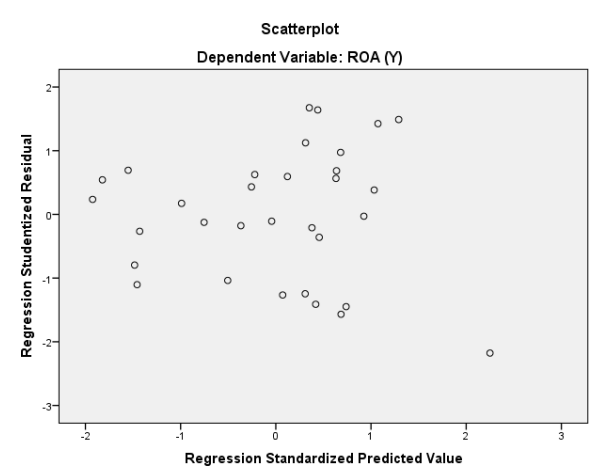

Sumber: Data primer yang diolah, 2021.

Gambar 3. Hasil Uji Heteroskedastisitas

Hasil uji heteroskedastisitas pada gambar 3, menunjukkan tidak terdapat pola tertentu dan tidak menyebar diatas maupun dibawah angka nol pada sumbu y, maka dapat disimpulkan tidak ada gejala heteroskedastisitas.

\section{Uji Autokorelasi}

Tabel 3. Hasil Uji Autokorelasi Model Summaryb

\begin{tabular}{|l|l|l|l|l|l|}
\hline Model & $\mathrm{R}$ & $\begin{array}{l}\mathrm{R} \\
\text { Square }\end{array}$ & $\begin{array}{l}\text { Adjusted } \\
\text { R Square }\end{array}$ & $\begin{array}{l}\text { Std. Error of } \\
\text { the Estimate }\end{array}$ & $\begin{array}{l}\text { Durbin- } \\
\text { Watson }\end{array}$ \\
\hline 1 &, $489^{\mathrm{a}}$ &, 239 &, 186 & 1,45836 & 2,006 \\
\hline
\end{tabular}

Sumber: Data primer yang diolah, 2021.

Hasil uji autokorelasi pada tabel 3, nilai du dicari pada distribusi nilai tabel durbin watson berdasarkan k (2), dan N (32) dengan signifikansi $5 \%$. Du $(1,574)<$ durbin watson $(2,006)$ $<4$-du (2,426). Ini menunjukan tidak ada gejala autokorelasi.

\section{Analisis Korelasi}

Tabel 4. Hasil Analisis Korelasi

Correlations

\begin{tabular}{|c|c|c|c|c|}
\hline & & ROA (Y) & $\begin{array}{l}\text { NPL } \\
\text { (X1) }\end{array}$ & CAR (X2) \\
\hline \multirow{3}{*}{$\begin{array}{l}\text { Pearson } \\
\text { Correlation }\end{array}$} & ROA (Y) & 1,000 &,- 134 & ,487 \\
\hline & NPL (X1) &,- 134 & 1,000 &,- 192 \\
\hline & CAR (X2) & ,487 &,- 192 & 1,000 \\
\hline \multirow[t]{3}{*}{ Sig. (1-ta1led) } & ROA (Y) & . & ,232 & ,002 \\
\hline & NPL (X1) & ,232 & . & , 146 \\
\hline & CAR (X2) & ,002 & , 146 & . \\
\hline \multirow[t]{3}{*}{$\mathrm{N}$} & ROA (Y) & 32 & 32 & 32 \\
\hline & NPL (X1) & 32 & 32 & 32 \\
\hline & CAR (X2) & 32 & 32 & 32 \\
\hline
\end{tabular}

Sumber: Data primer yang diolah, 2021.

Hasil analisis korelasi pada tabel 4 menunjukkan signifikansi sebesar 0,232. Artinya implikasi NPL terhadap profitabilitas (ROA) tidak 
berkorelasi dengan nilai signifikansi $>0,05$, yang berarti tidak terdapat hubungan antara NPL terhadap profitabilitas perusahaan. Korelasi sebesar -0,134 menunjukkan implikasi NPL terhadap profitabilitas perusahaan memiliki hubungan negatif dengan tingkat keeratan yang sangat rendah karena berada pada interval $0,00-0,20$. Artinya jika NPL meningkat maka akan berimplikasi terhadap penurunan profitabilitas.

\section{Analisis Koefisien Determinasi}

Tabel 5. Hasil Analisis Koefisien Determinasi NPL Terhadap Profitabilitas

Model Summary

\begin{tabular}{|l|c|r|r|r|r|}
\hline Model & $\mathrm{R}$ & $\begin{array}{c}\mathrm{R} \\
\text { Square }\end{array}$ & $\begin{array}{c}\text { Adjusted R } \\
\text { Square }\end{array}$ & $\begin{array}{c}\text { Std. Error of } \\
\text { the Estimate }\end{array}$ & $\begin{array}{c}\text { Durbin- } \\
\text { Watson }\end{array}$ \\
\hline 1 &, $134^{\mathrm{a}}$ &, 018 &,- 015 & 1,62870 & 1,412 \\
\hline
\end{tabular}

a. Predictors: (Constant), NPL

b. Dependent Variable: ROA

Sumber: Data primer yang diolah, 2021.

Tabel 5 menunjukkan nilai R-Squared sebesar 0,018. Menurut perhitungan koefisien determinasi :

$$
\begin{aligned}
\mathrm{Kd} & : \mathrm{r} 2 \times 100 \% \\
& : 0,018 \times 100 \% \\
& : 0,018 \\
& : 1,8 \%
\end{aligned}
$$

Hal ini menunjukkan besarnya pengaruh NPL terhadap profitabilitas sebesar $1,8 \%$ dan sisanya $98,2 \%$ dipengaruhi oleh faktor lain diluar dari penelitian ini.

Tabel 6. Hasil Analisis Koefisien Determinasi CAR Terhadap Profitabilitas

Model Summary

\begin{tabular}{|l|l|r|r|r|r|}
\hline Model & $\mathrm{R}$ & $\begin{array}{c}\mathrm{R} \\
\text { Square }\end{array}$ & $\begin{array}{c}\text { Adjusted R } \\
\text { Square }\end{array}$ & $\begin{array}{c}\text { Std. Error of } \\
\text { the Estimate }\end{array}$ & $\begin{array}{c}\text { Durbin- } \\
\text { Watson }\end{array}$ \\
\hline 1 &, $487^{\mathrm{a}}$ &, 237 &, 212 & 1,43548 & 2,011 \\
\hline
\end{tabular}

a. Predictors: (Constant), CAR

b. Dependent Variable: ROA

Sumber: Data primer yang diolah, 2021.

Tabel 6 menunjukkan nilai R-Squared sebesar 0,237. Menurut perhitungan koefisien determinasi :

$\mathrm{Kd}$

$$
\begin{aligned}
& : \mathrm{r} 2 \times 100 \% \\
& : 0,237 \times 100 \% \\
& : 0,237 \\
& : 23,7 \%
\end{aligned}
$$

\begin{tabular}{|c|c|c|c|c|c|c|c|}
\hline \multicolumn{3}{|c|}{$\begin{array}{l}\text { Unstandardized } \\
\text { Coefficients }\end{array}$} & \multirow{2}{*}{$\begin{array}{c}\begin{array}{c}\text { Standar } \\
\text { dized } \\
\text { Coefficie } \\
\text { nts }\end{array} \\
\text { Beta } \\
\end{array}$} & \multirow[b]{2}{*}{$\mathrm{t}$} & \multirow[b]{2}{*}{ Sig. } & \multicolumn{2}{|c|}{$\begin{array}{l}\text { Collinearity } \\
\text { Statistics }\end{array}$} \\
\hline Model & B & $\begin{array}{l}\text { Std. } \\
\text { Error }\end{array}$ & & & & $\begin{array}{c}\text { Toleran } \\
\text { ce }\end{array}$ & VIF \\
\hline (Constant) & $-1,110$ & 2,968 & &,- 374 & ,711 & & \\
\hline NPL (X1) &,- 349 & 1,355 &,- 042 &,- 257 & ,799 & 963 & 1,038 \\
\hline CAR (X2) & 246 & ,085 & ,479 & 2,901 & ,007 & ,963 & 1,038 \\
\hline
\end{tabular}

Hal ini menunjukkan besarnya pengaruh CAR terhadap profitabilitas sebesar $23,7 \%$ dan sisanya $76,3 \%$ dipengaruhi oleh faktor lain diluar dari penelitian ini.

\section{Analisis Regresi Linier Berganda}

Tabel 7. Hasil Analisis Regresi Linier Berganda

a. Dependent Variable: ROA $(\mathrm{Y})$

Sumber: Data primer yang diolah, 2021

Berdasarkan tabel 7, maka dapat diketahui persamaan regresi :

$$
\mathrm{Y}=-1,110-0,349 \mathrm{X} 1+0,246 \mathrm{X} 2
$$

Persamaan regresi tersebut dapat diterjemahkan :

1. Konstanta (a) memiliki nilai sebesar -1.110 dan bertanda negatif, menyatakan bahwa jika NPL dan CAR meningkat sebesar Rp. 1,- maka akan menyebabkan nilai profitabilitas turun sebesar 1,110 .

2. Nilai koefisien regresi variabel NPL adalah sebesar $-0,349$ dan bertanda negatif, artinya jika variabel NPL meningkat sebesar Rp. 1,- maka akan menyebabkan nilai profitabilitas turun

\begin{tabular}{|c|c|c|c|c|c|c|c|c|}
\hline & & $\begin{array}{l}\text { Unstan } \\
\text { Coeffic }\end{array}$ & $\begin{array}{l}\text { rrdized } \\
\text { nts }\end{array}$ & $\begin{array}{c}\text { Standardiz } \\
\text { ed } \\
\text { Coefficient } \\
\text { S }\end{array}$ & & & $\begin{array}{r}\text { Collin } \\
\text { Stati }\end{array}$ & \\
\hline & & B & $\begin{array}{l}\text { Std. } \\
\text { Error }\end{array}$ & Beta & $\mathrm{T}$ & Sig. & $\begin{array}{c}\text { Tolera } \\
\text { nce }\end{array}$ & VIF \\
\hline 1 & (Constant) & $1,110^{-}$ & 2,968 & & ,374 & ,711 & & \\
\hline & NPL (X1) &,- 349 & 1,355 &,- 042 & ,257 & ,799 & ,963 & 1,038 \\
\hline & $\overline{C A R}(\mathrm{X} 2)$ & ,246 & ,085 & ,479 & $\begin{array}{r}2,90 \\
1\end{array}$ & ,007 & ,963 & 1,038 \\
\hline
\end{tabular}
sebesar - 0,349.

3. Nilai koefisien regresi variabel CAR adalah sebesar 0,246 dan bertanda positif, artinya jika variabel CAR meningkat sebesar Rp. 1,- maka akan menyebabkan nilai profitabilitas naik sebesar 0,246 poin.

\section{Uji t}

Tabel 8. Hasil Uji t NPL Terhadap Profitabilitas

Sumber: Data primer yang diolah, 2021

Hasil uji t parsial pada tabel 8 menunjukkan signifikansi untuk NPL sebesar 0,799 yang berarti NPL tidak berpengaruh terhadap profitabilitas karena mempunyai signifikansi $>0,05$. Nilai $t_{\text {hitung }}$ untuk NPL sebesar - 0,257 <2,045 ( $\left.\mathrm{t}_{\text {tabel }}\right)$ yang berarti NPL tidak berpengaruh terhadap profitabilitas. 
Tabel 9. Hasil Uji t CAR Terhadap Profitabilitas

\begin{tabular}{|c|c|c|c|c|c|c|c|}
\hline \multicolumn{3}{|c|}{$\begin{array}{l}\text { Unstandardized } \\
\text { Coefficients }\end{array}$} & \multirow{2}{*}{$\begin{array}{c}\begin{array}{c}\text { Standardi } \\
\text { zed } \\
\text { Coefficie } \\
\text { nts }\end{array} \\
\text { Beta }\end{array}$} & \multirow[b]{2}{*}{$t$} & \multirow[b]{2}{*}{ Sig. } & \multicolumn{2}{|c|}{$\begin{array}{l}\text { Collinearity } \\
\text { Statistics }\end{array}$} \\
\hline Model & B & $\begin{array}{l}\text { Std. } \\
\text { Error }\end{array}$ & & & & $\begin{array}{l}\text { Toleran } \\
\text { ce }\end{array}$ & VIF \\
\hline \begin{tabular}{l|l}
1 & (Constant)
\end{tabular} & $-1,110$ & 2,968 & &,- 374 & ,711 & & \\
\hline \begin{tabular}{|l|l|} 
NPL (X1) \\
\end{tabular} &,- 349 & 1,355 & $\begin{array}{l}-, 042 \\
\end{array}$ &,- 257 & ,799 & ,963 & 1,038 \\
\hline CAR (X2) & ,246 & ,085 & ,479 & 2,901 & ,007 & ,963 & 1,038 \\
\hline
\end{tabular}

a. Dependent Variable: ROA (Y)

Sumber: Data primer yang diolah, 2021.

Hasil uji t parsial pada tabel 9 , menunjukkan signifikansi untuk CAR sebesar 0,007 yang berarti CAR berpengaruh terhadap profitabilitas karena mempunyai signifikansi $<0.05$. Nilai $t_{\text {hitung }}$ untuk CAR sebesar 2,901 > 2,045 ( $\left.\mathrm{t}_{\text {tabel }}\right)$ yang berarti CAR berpengaruh terhadap profitabilitas.

\section{Uji F}

Tabel 10. Hasil Analisis Regresi Linier Berganda NPL Terhadap Profitabilitas ANOVAa

\begin{tabular}{|c|c|c|c|c|c|c|}
\hline \multicolumn{2}{|c|}{ Model } & $\begin{array}{l}\text { Sum of } \\
\text { Squares }\end{array}$ & Df & $\begin{array}{c}\text { Mean } \\
\text { Square }\end{array}$ & $\mathrm{F}$ & Sig. \\
\hline 1 & $\begin{array}{l}\text { Regressi } \\
\text { on }\end{array}$ & 19,365 & 2 & 9,682 & \multirow{2}{*}{4,552} & \multirow{2}{*}{, $019^{b}$} \\
\hline & Residual & 61,678 & 29 & 2,127 & & \\
\hline & Total & 81,042 & 31 & & & \\
\hline
\end{tabular}

Tabel 10 menunjukkan nilai signifikansi untuk pengaruh $\mathrm{X} 1$ dan $\mathrm{X} 2$ secara simultan terhadap $\mathrm{Y}$ adalah sebesar $0,019<0,05$ dan nilai $F$ hitung 4,552 $>3,32$, sehingga dapat disimpulkan bahwa pengaruh NPL dan CAR dapat diterima yang berarti terdapat impak NPL dan CAR secara simultan terhadap Profitabilitas.

Impak NPL dengan profitabilitas sebesar 1,8\% dan nilai signifikan sebesar 0,799>0,05 dan $t_{\text {hitung }}$ $0,257<\mathrm{t}_{\text {tabel }} 2,045$ menunjukkan bahwa NPL tidak berpengaruh terhadap profitabilitas. Hal ini tidak sesuai dengan teori yang disampaikan oleh (Kasmir, 2017) yang menyatakan ketika mengeluarkan pinjaman dalam jumlah besar maka yang menjadi kriteria ada pada kualitas kredit. Artinya, semakin tinggi kualitas kredit yang diberikan, maka semakin rendah risiko kredit bermasalah.

Impak CAR dengan profitabilitas sebesar $23,7 \%$ dan nilai signifikansi sebesar 0,007 > 0,05 dan $\mathrm{t}_{\text {hitung }} 2,901>\mathrm{t}_{\text {tabel }} 2,045$ menunjukkan bahwa CAR berpengaruh terhadap profitabilitas. Ini sesuai dengan teori yang disampaikan (Hanafi \& Halim, 2016) yang menyatakan bahwa profitabilitas adalah rasio yang umum digunakan untuk mengukur kemampuan perusahaan dalam menghasilkan laba bersih berdasarkan tingkat aset dan tingkat aset yang baik akan mempengaruhi pengembalian (return).

Impak NPL dan CAR terhadap profitabilitas (ROA) secara simultan diterima. Hal ini sesuai dengan hasil penelitian (Kosasih et al., 2021) yang menyatakan CAR, Loan to Deposit Ratio (LDR) dan NPL berimplikasi terhadap profitabilitas. Jadi semakin tinggi NPL, semakin rendah kinerja bank dan semakin rendah profitabilitas, dan sebaliknya; semakin tinggi CAR maka semakin tinggi kinerja bank dalam mencapai profitabilitas, begitu juga sebaliknya (Kasmir, 2017). Kemudian hasil penelitian dari (Murdiyanto, 2012) menyatakan faktor-faktor yang berpengaruh terhadap penyaluran kredit pada perbankan antara lain Dana Pihak Ketiga, CAR, NPL dan suku bunga Sertifikat Bank Indonesia (SBI).

\section{KESIMPULAN}

Berdasarkan uraian hasil dan pembahasan diatas maka disimpulkan bahwa NPL dan CAR mempunyai determinasi yang tinggi terhadap profitabilitas artinya perusahaan mampu memberikan kualitas kredit yang tinggi dan kualitas kecukupan modal yang baik untuk menghindari adanya risiko kerugian yang mungkin terjadi sehingga berpengaruh terhadap tingkat laba yang diinginkan oleh perusahaan.

Bagi perusahaan agar dapat fokus pada faktor NPL, karena semakin tinggi NPL maka dikhawatirkan kualitas kredit semakin menurun sehingga kemungkinan kredit bermasalah semakin tinggi. Kemudian dari sisi CAR agar perusahaan mampu meningkatkan modal agar terhindar dari setiap kredit bermasalah.

Penelitian selanjutnya bisa dikembangkan lebih jauh dengan memasukkan faktor-faktor lainnya yang berpengaruh terhadap profitabilitas, seperti Loan to Deposit Ratio (LDR), BI Rate, biaya operasional dan Net Interest Margin.

\section{REFERENSI}

Amelia, R. W., \& Sunarsi, D. (2020). Pengaruh Return on Asset Dan Return on Equity Terhadap Debt To Equity Ratio Pada Pt. Kalbe Farma, Tbk. Ad-Deenar: Jurnal Ekonomi Dan Bisnis Islam, 4(01), 105. https://doi.org/10.30868/ad.v4i01.738

Anastasiou, D., Louri, H., \& Tsionas, M. (2019). Nonperforming loans in the euro area: Are core-periphery banking markets fragmented? International Journal of Finance and Economics, 24(1), 97-112. https://doi.org/10.1002/ijfe.1651

Anggari, N. L. S., \& Dana, I. M. (2020). The Effect of Capital Adequacy Ratio , Third Party Funds , Loan to Deposit Ratio , Bank Size on Profitability in Banking Companies on IDX. American Journal of Humanities and Social Sciences Research (AJHSSR), 4(12), 334-338.

Ashraf, B., Arshad, S., \& Hu, Y. (2016). Capital Regulation and Bank Risk-Taking Behavior: 
Evidence from Pakistan. International Journal of Financial Studies, 4(3), 16. https://doi.org/10.3390/ijfs4030016

Basuki, A. T. (2017). Ekonometrika dan Aplikasi Dalam Ekonomi. Yogyakarta: Danisa Media.

Beck, R., Jakubik, P., \& Piloiu, A. (2015). Key Determinants of Non-performing Loans: New Evidence from a Global Sample. Open Economies Review, 26(3), 525-550. https://doi.org/10.1007/s11079-015-9358-8

Creswell, J. W. (2016). Research Design: Pendekatan Metode Kualitatif, Kuantitatif dan Campuran (4th ed.). Yogyakarta: Pustaka Pelajar.

Espinoza, R., \& Prasad, A. (2010). Nonperforming Loans in the GCC Banking System and their Macroeconomic Effects. IMF Working Papers, 10(224), https://doi.org/10.5089/9781455208890.001

Ghozali, I. (2016). Aplikasi Analisis Multivariate dengan Program SPSS (4th ed.). Semarang: Badan Penerbit Universitas Diponegoro.

Gilbert, R. A., \& Hazen, J. H. (2001). As economy flounders, do we see a rise in problem loans. Federal Reserve Bank of St. Louis, II(4), 45-65. Retrieved from https://www.stlouisfed.org/publications/central -banker/winter-2001/as-economy-floundersdo-we-see-a-rise-in-problem-loans

Gunawan, A. (2020). 2019, Adira Finance Cetak Laba Rp2,1 Triliun Artikel ini telah tayang di Bisnis.com dengan judul "2019, Adira Finance Cetak Laba Rp2,1 Triliun”, Klik selengkapnya di sini: https://finansial.bisnis.com/read/20200221/89/ 1204343/2019-adira-finance-cetak-laba.

Retrieved May 2, 2021, from https://finansial.bisnis.com/read/20200221/89/ 1204343/2019-adira-finance-cetak-laba-rp21triliun

Hanafi, M. M., \& Halim, A. (2016). Analisis Laporan Keuangan. Yogyakarta: UPP STIM YKPN.

Indonesia, B. Surat Edaran Bank Indonesia (SE BI) No.13/ 24 /DPNP tentang Penilaian Tingkat Kesehatan Bank Umum (2011).

Janie, D. N. A. (2012). Statistik Deskriptif \& Regresi Linier Berganda Dengan SPSS. Semarang: Semarang University Press.

Kasmir. (2017). Analisis Laporan Keuangan. Jakarta: PT. Rajagrafindo Persada.

Khan, M. A., Siddique, A., \& Sarwar, Z. (2020). Determinants of non-performing loans in the banking sector in developing state. Asian Journal of Accounting Research, 5(1), 135145. https://doi.org/10.1108/ajar-10-20190080

Kosasih, N. J., Murni, S., Rate, P. V, Faktor, A., Dan,
I., Terhadap, E., \& Pada, P. (2021). Analisis Faktor Internal Dan Eksternal Terhadap Profitabilitas Pada Sektor Perbankan Yang Terdaftar Di Bursa Efek Indonesia Periode 2014-2018. Jurnal EMBA: Jurnal Riset Ekonomi, Manajemen, Bisnis Dan Akuntansi, 9(2), 336-347. https://doi.org/10.35794/emba.v9i2.33454

Moradi, Z. S., Mirzaeenejad, M., \& Geraeenejad, G. (2016). Effect of Bank-Based or Market-Based Financial Systems on Income Distribution in Selected Countries. Procedia Economics and Finance, 36(16), 510-521. https://doi.org/10.1016/s2212-5671(16)300673

Murdiyanto, A. (2012). Faktor-Faktor Yang Berpengaruh Dalam Penentuan Penyaluran Kredit Perbankan Studi Pada Bank Umum Di Indonesia Periode Tahun 2006 - 2011. Conference In Business, Accounting, And Management (CBAM), 1(1), 61-75. Retrieved from

http://jurnal.unissula.ac.id/index.php/cbam/arti cle/view/123/99

Neuman, W. L. (2014). Social Research Methods: Qualitative and Quantitative Approaches (7th ed.). Boca Raton: Pearson Educational Limited.

Ovier, A. (2021). Industri Multifinance Mampu Bertahan di Tengah Tekanan. Retrieved May 1, 2021, from https://www.beritasatu.com/ekonomi/752887/i ndustri-multifinance-mampu-bertahan-ditengah-tekanan

Pattiruhu, J. R., \& Paais, M. (2020). Effect of Liquidity, Profitability, Leverage, and Firm Size on Dividend Policy. Journal of Asian Finance, Economics and Business, 7(10), 3542.

https://doi.org/10.13106/jafeb.2020.vol7.no10. 035

Rostami, S., Rostami, Z., \& Kohansal, S. (2016). The Effect of Corporate Governance Components on Return on Assets and Stock Return of Companies Listed in Tehran Stock Exchange. Procedia Economics and Finance, 36(16), 137-146. https://doi.org/10.1016/s22125671(16)30025-9

Sánchez Serrano, A. (2021). The impact of nonperforming loans on bank lending in Europe: An empirical analysis. North American Journal of Economics and Finance, 55, 101312. https://doi.org/10.1016/j.najef.2020.101312

Sari, N. P., \& Khafid, M. (2020). Peran Kepemilikan Manajerial dalam Memoderasi Pengaruh Profitabilitas, Leverage, Ukuran Perusahaan, Kebijakan Dividen Terhadap Manajemen Laba pada Perusahaan BUMN. Moneter - Jurnal 
Akuntansi Dan Keuangan, 7(2), 222-231. https://doi.org/10.31294/moneter.v7i2.8773

Sitompul, R. M. A., Bukit, R., \& Erwin, K. (2020). the Effect of Liquidity, Solvability, Profitability, and Non Performing Financing on Firm Value With Intellectual Capital As Moderating Variables in Multifinance Companies Listed on Indonesia Stock Exchange in 2015-2018. Journal of Public Budgeting, Accounting and Finance, 3(1), 1689-1699.

Sugiarti, H., \& Megawarni, A. (2012). Konsistensi koefisien determinasi sebagai ukuran kesesuaian model pada regresi robust. Jurnal Matematika, Sains, Dan Teknologi, 13(2), 65-
72. Retrieved from https://jurnal.ut.ac.id/index.php/jmst/article/vie w/484/472

Sugiyono. (2017). Metode Penelitian Kuantitatif Kualitatif dan $R \& D$. Bandung: Alfabeta.

Utami, M. T., \& Manda, G. S. (2021). Pengaruh Working Capital Turnover (Wct), Current Ratio (Cr), Dan Total Assets Turnover (Tato) Terhadap Profitabilitas. Moneter - Jurnal Akuntansi Dan Keuangan, 8(1), 1-8. https://doi.org/10.31294/moneter.v8i1.8798

Yuliara, I. M. (2016). Regresi Linier Berganda. Denpasar. 